Volume 2, Number 2, 2016

\title{
Optimization of Gas Dynamical Subsystem of Transducers for Measurement of Gas Flow Temperature
}

\author{
Vasyl Fedynets", Ihor Vasylkivskyi, Yaroslav Yusyk \\ Lviv Polytechnic National University, 12 S. Bandera St., Lviv, 79013, Ukraine
}

Received: November 11, 2016. Revised: December 12, 2016. Accepted: December 26, 2016.

(c) 2016 The Authors. Published by Lviv Polytechnic National University.

\begin{abstract}
The main types of errors which occur while measuring the temperature of gas flows, including flows of fuels, are determined by the conditions of thermal balance at the interaction of the sensor of the temperature transducer (TT) with the gas flow via convection, radiation and conduction. The limited TT capacity to track flow temperature variation should also be taken into consideration. For high gas flow speeds (over $50 \mathrm{~m} / \mathrm{s}$ ), another type of error (the so-called speed error) arises from the transformation of part of kinetic energy of the flow into thermal energy. A comprehensive analytical study of the combined influence of all the major factors on the total error of gas flow temperature measurement with a particular TT is actually impracticable, since some relationships describing the character of influence of this or that factor can be obtained only by experiment. Therefore, in practice, each error type is analysed separately, assuming that no other types of error occur, and the total error of measurement is regarded as superposition of separate error types. For convenience of analysis, TT is represented as a combination of separate units, each with its own components of the error. TT for gas flow temperature measurements appears as three units, such as gas dynamic, thermal and electrical, connected in series. The gas dynamic subsystem transforms the thermodynamic temperature $T(\tau)$ of the gas flow at the TT input into the deceleration temperature $T_{\Pi T T}(\tau)$ at the temperature sensor input and is characterized by the speed error. The defining characteristic of the gas dynamic subsystem is the TT recovery factor, which is why the paper discusses the methods and means of ensuring the constancy of the recovery factor.
\end{abstract}

Keywords: gas flow; measurement; heat exchange; temperature; temperature transducer.

\section{Introduction}

The accuracy of gas flow temperature measurement depends not only on the errors of the measuring devices, but also on the measurement conditions, TT installation, etc. This is due to the fact that, when using contact temperature measurement methods, TT is in direct contact with the medium the temperature of which is being measured. In these conditions, TT is a foreign object which, to some extent, disturbs the initial temperature field of the medium in the place of TT installation. Any TT shows only its own temperature, or specifically the temperature of the sensor, which in a general case differs from the deceleration temperature. The difference between the TT readings and deceleration temperature is the error of gas flow temperature measurement. This error is determined by the thermal balance conditions at the interaction of the TT sensor with the gas flow via convection, radiation and conduction (conductive heat transfer). Another complication at the error evaluation is that heat-transfer properties of both thermoelectric and construction materials are also temperature-dependent.

At high speeds of gas flow, the so-called speed error caused by the incomplete transformation of the kinetic energy of the flowing gas into the thermal energy in the wall layer surrounding the TT sensor occurs.

When measuring temperature of the high-speed gas flow, irrespective of the actual temperature, the temperature of the TT sensor is higher than that of the medium and the surrounding walls. As the flow temperature rises, the

\footnotetext{
*Corresponding author. Email address: v.fedynets@ukr.net
} 
difference between the TT temperature and that of the walls will increase. Thereat, the TT sensor will be losing part of the heat obtained from the flow.

Finally, if the flow temperature is not stationary, than the heat capacity of the sensor is the reason why the TT lags behind in recording time variation of the flow temperature. In these conditions, the dynamic error of measurement appears.

Therefore, radiation, conductive heat transfer, transformation of the kinetic energy into thermal energy depending on the flow speed, as well as the limited TT capacity to monitor the flow temperature variation without lag determine the main types of error occurring in gas flow temperature measurements. In a general case, these errors are defined by dimensions and physical properties of the TT sensor, as well as by the physical properties and parameters of the flow passing over the sensor.

\section{Analysis of the literature}

A comprehensive analytical study of the combined influence of all the major factors on the total error of gas flow temperature measurement using a specific TT with a complex structure cannot be practically undertaken, since some relationships which describe the character of influence of this or that factor can be obtained only by experiment. This is due to the fact that the evaluation of the effect of various factors is always approximate. In practice, as a rule, each type of error is analysed separately on the assumption that no other type of error occurs, and the total error of measurement can be considered as superposition of separate error types [1-3].

Therefore, for convenience of analysis, in [4] it is proposed that TT should be represented in the form of separate elementary units with their own transformation operators and error components. Thereat, an elementary unit is assumed to be an aggregate of transformation means and methods combined on the basis of specific features.

Such TT representation makes it convenient to carry out a step-by-step optimization with respect to the units of the equivalent circuit diagram. Optimality criteria, constraint functions and influencing factors can be different for each unit.

For the gas flow TT, the equivalent circuit diagram of transformation is presented in [5] as three series units (subsystems), namely gas dynamic, thermal and electrical. The gas dynamic subsystem transforms the thermodynamic temperature $T(\tau)$ of the gas flow at the TT input into the deceleration temperature $T_{\Pi T}(\tau)$ at the temperature sensor input and is characterized by the speed error. The thermal subsystem transforms this temperature into the equilibrium temperature $\left.T_{P \Pi T} \tau\right)$ of the temperature sensor, which expresses its enthalpy and is characterized by components of the error stemming from convection, radiation and conduction, and the error originating from the sources of energy in TT. The electrical subsystem transforms the temperature $T_{P \Pi T}(\tau)$ into the output electrical signal $y_{\Pi T}(\tau)$.

\section{Objectives}

The defining characteristic of the gas dynamic subsystem is the recovery factor of TT, and this research aims at optimization of the gas dynamic system, which includes the determination of methods and means ensuring the constancy of the recovery factor at interference and for the assumed restrictions.

\section{Theoretical and experimental studies}

The speed error $\Delta t_{u \varepsilon}$ of gas flow temperature measurement, which is the main one for the TT gas dynamic subsystem, is defined by the recovery factor and the gas speed near the sensor:

$$
\Delta t_{u \varepsilon}=T_{P \Pi T}-T_{0}=-(1-r) \frac{V^{2}}{2 C_{P}},
$$

where $T_{0}$ is the deceleration temperature; $V$ is the oncoming flow speed; $C_{P}$ is the heat capacity of the flow at a constant volume.

The calculations based on the equation (1) show that, for instance, for air the value of $\Delta t_{u \varepsilon}$ is $1 ; 2 ; 5 ; 20 ; 500 \mathrm{~K}$ for the speeds $50 ; 100 ; 200$ and $1000 \mathrm{~m} / \mathrm{s}$, respectively, and for superheated water steam $\Delta t_{u s}=0.4 \mathrm{~K}$ at the speed of 
$50 \mathrm{~m} / \mathrm{s}$. For the flow speed below $50 \mathrm{~m} / \mathrm{s}, \Delta t_{u s}$ is relatively low, which is why during practical measurements of temperature this speed is, as a rule, considered to be the upper limit of the range of moderate speeds.

The analysis of (1) shows that the speed error depends on the gas flow speed in the area of the sensor and TT recovery factor which, in its turn, is determined by the flow speed, TT dimensions and design parameters.

Therefore, the optimization of the gas dynamic subsystem (speed error optimization) must include the identification of the methods and means ensuring the constancy of the recovery factor and artificial reduction of the speed of the sensor flow-around, as compared to the oncoming flow speed at interference and for the assumed restrictions.

The restrictions can include the requirements to ensure the following factors:

1) optimal conditions of convective heat transfer between TT and the target medium;

2) minimum distortion of the temperature field of the process under study;

3) TT physical and technical implementation, etc.

Thereat, the criterion of minimum speed error $\Delta t_{\text {us }}$ will be the optimality criterion.

For the optimization of the gas dynamic system, it is necessary to identify the conditions which would ensure the minimum change of the TT recovery factor $r$, i.e.

$$
\Delta r \rightarrow 0,
$$

if there are losses and for the assumed restrictions.

To establish the requirements to the TT design which would satisfy the optimization condition, in [5] the recovery factor was presented as a function of the recovery factors of the deceleration chamber $r_{\kappa, 2}$ and sensor $r_{4}$ :

$$
r=r_{\kappa .2}-r_{\kappa .2} r_{\psi e}+r_{\psi e}=r_{\kappa .2}\left(1-r_{\psi e}+\frac{r_{\psi e}}{r_{k .2}}\right) .
$$

The equation (3) shows that the more stable and closer to the unit the recovery factors of the deceleration chamber and sensor are, the more stable the TT recovery factor is.

The optimization of the gas dynamic system requires the analysis of the TT gas dynamic characteristics. These characteristics have been studied in a great number of researches carried out in the two following areas:

- analytical definition of the equilibrium temperature of TT which is flowed around by gas;

- experimental determination of the recovery factor.

As it was mentioned in [5], the available analytical solutions provide for evaluating the equilibrium temperature and recovery factor only for the flat plate. For cylinder-shaped TT characterized by another type of flow-around (stalled flow-around), the problem has no accurate analytical solution [6]. Because of this, there were experimental studies aimed at evaluating the equilibrium temperature and recovery factor for TT devices of various shapes.

The experimental studies were carried out in the stationary flow-around conditions, as in case of non-stationary flow-around the recovery factor is a variable whose character and value cannot be determined due to the TT thermal inertia.

Based on the outcomes of the numerous studies $[7,8]$ and according to the author's research, the following conclusions have been made.

1. The highest and the most stable recovery factors are observed for plate sensors and those with elliptical and round cross-section for a longitudinal flow-around. In case of a transverse flow-around, sensors with round crosssections have the lowest and the least stable recovery factor.

2. According to the character of the recovery factor variation in plate sensors and elliptical and round crosssection sensors for a longitudinal flow-around, depending on Reynolds number Re and Mach number $\mathbf{M}$, the following three areas are distinguished: 
a) the laminar flow region, in which $r_{4 e}$ is a constant value equal to 0.84 . It is called the first self-similarity region;

b) the transition region, in which $r_{4 e}$ increases with an increase in $\mathbf{R e}$ and $\mathbf{M}$ numbers;

c) the turbulent flow region (the second self-similarity region), in which $r_{u e}$ is constant and equals 0.9.

3. According to the character of the TT recovery factor variation in round cross-section sensors for a transverse flow-around, depending on $\mathbf{R e}$ and $\mathbf{M}$ numbers, the following four areas are distinguished:

a) the region with low $\mathbf{R e}$ and $\mathbf{M}$ numbers $(\mathbf{R e}<3000$ and $0.01 \leq \mathbf{M} \leq 0.2)$, in which $r_{\text {ue }}$ is a constant value (the first self-similarity region);

b) the region with $\mathbf{R e}$ number falling into the range from 3000 to 120000 and $\mathbf{M}$ number from 0.7 to 1.0, where $r_{4 e}$ increases, as $\mathbf{R e}$ and $\mathbf{M}$ numbers increase;

c) the region with $\mathbf{R e}$ number falling into the range from 20000 to 20000 and $\mathbf{M}$ number from 0.2 to 0.7 , in which $r_{\text {ч }}$ is a constant value (the second self-similarity region);

d) the region with $\mathbf{R e}>120000$ and $\mathbf{M}>1$, in which $r_{4 e}$ increases, as Re and $\mathbf{M}$ numbers increase.

4. Heat transfer due to the conductance from the sensor to the fittings and the effect of the radiation between the sensor and the protection fitting can cause a substantial distortion of the recovery factor. Therefore, at temperatures up to $300^{\circ} \mathrm{C}$, when heat losses due to conductance and radiation are insignificant, the TT error is mainly defined by the speed error. In this case, the recovery factor being known will allow one to make the necessary corrections connected with the systematic error of the incomplete recovery of the deceleration temperature.

At temperatures exceeding $300{ }^{\circ} \mathrm{C}$, the proportions of errors stemming from conductance and radiation become commensurable with or even exceed the speed error. Due to this, the recovery factor stops being a measure of the kinetic energy which transforms into the thermal energy. In this case, it is necessary to perform dynamic calibration of TT by comparing its readings with the readings of the control TT at the temperatures and Mach numbers close to or equal to those typical for TT use. If TT is designed in such a way that the error resulting from heat transfer due to conductance and radiation between the sensor and protection fittings is insignificant, then the total recovery factor can be evaluated using the formula (3). For example, for $r_{\text {че }}=0.86$ and the ratio of the speeds in the deceleration chamber $V_{\kappa .2}$ to the oncoming flow speed $V\left(V_{\kappa .2} / V\right)=1 / 8$, the TT recovery factor $r$ is approximately 0.998 .

Based on the above-presented conclusions, the following main requirements to the TT design have been defined, which, if complied with, will ensure a sufficient stability of the recovery factor for the wide range of $\mathbf{R e}$ and $\mathbf{M}$ numbers variation:

a) for plate sensors and those with an elliptical cross-section, a longitudinal flow-around of TT by the oncoming flow should be ensured;

b) a transverse flow is acceptable for the sensors with a round cross-section;

c) the recovery factor should be independent of $\mathbf{R e}$ and $\mathbf{M}$ numbers;

d) the sensor should be protected against heat interaction with the surrounding elements.

To comply with the requirements c) and d), TT sensors should be installed within the aerodynamic chambers, namely the deceleration chamber with the conditions corresponding to the first self-similarity region or the critical speed chamber corresponding to the second self-similarity region, or into continuous-flow cylindrical chambers with conditions which correspond to those at the entry into the chamber. The schematic diagrams of the aerodynamic chambers are presented in the Fig. 1 below.

In the practice of gas flow temperature measurements, $\mathbf{M}$ number in the chamber should not exceed 0.2, i.e. a constant recovery factor should be ensured in the first self-similarity region.

In the experimental practice, for the artificial reduction of the speed of the flow around the sensor, TT with deceleration chambers is the most widely used. Such a TT has a high and stable recovery factor within a wide range of gas flow speed. The higher and more stable the recovery factor $r$ is, the higher TT performance is. TT is applicable for measuring the temperature of high-speed gas flows only if its recovery factor is a constant value within the wide range of Reynolds and Mach numbers. 


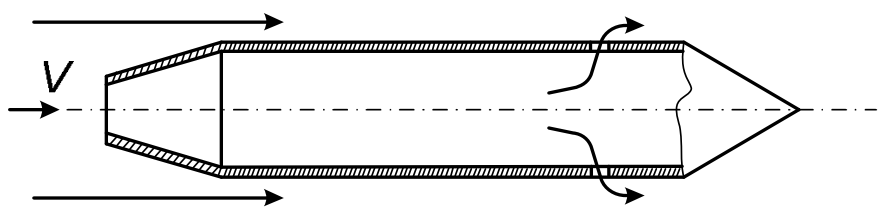

a)

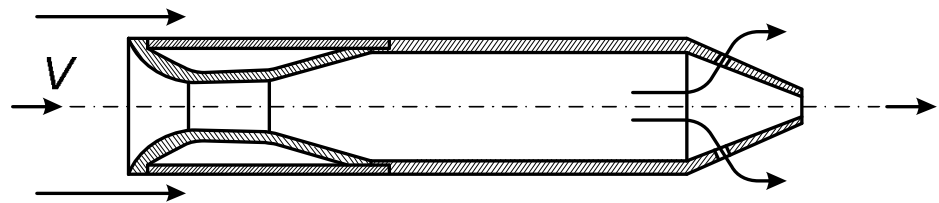

b)

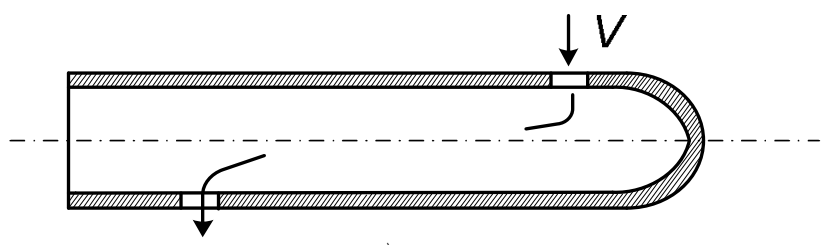

c)
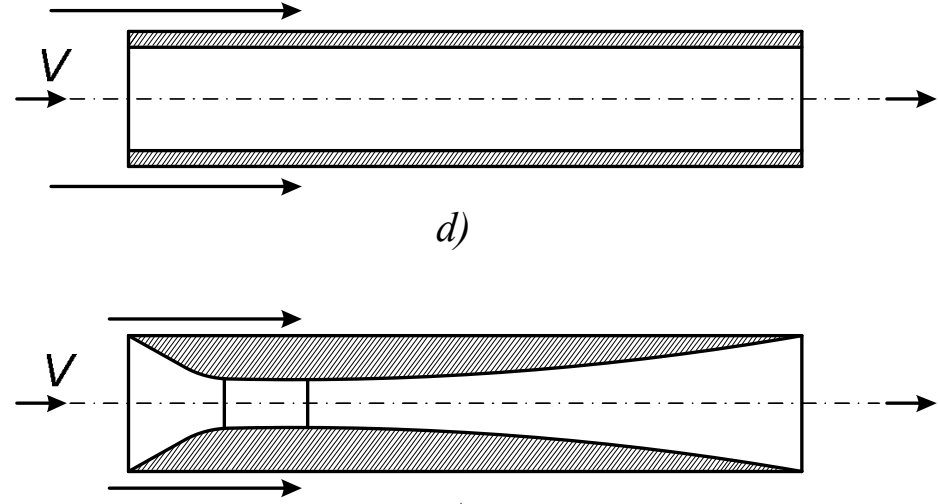

e)

Fig.1. The schematic diagrams of the aerodynamic chambers: a) deceleration chamber with the longitudinal flow-around and diverging entry; b) deceleration chamber with the longitudinal flow-around and converging entry; c) transverse flow-around chamber; d) cylindrical chamber with a constant cross-section; e) critical speed chamber

In research and experimental practice, temperature transducers with cylindrical and spherical deceleration chambers are most widely used. Such chambers make it possible to decelerate the gas flow in the place of TT location.

\section{Conclusions}

The results of the experimental studies conducted by various researchers $[3,7,8]$ and by the author of this paper showed that the recovery factor of TT with deceleration chambers is practically constant and stable within a wide range of Reynolds and Mach numbers. The TT recovery factor at a longitudinal flow-around within a wide range of the gas flow speed is $0.97 \ldots$ 0.98. At a transverse flow-around, the value of the recovery factor of TT with deceleration chambers (for sensors with round cross-sections) is always lower than that at a longitudinal flow-around and falls into the range $0.94 \ldots 0.95$.

An important advantage of the cylindrical deceleration chamber is the fact that the TT total recovery factor in this case is independent of the angle of attack of the oncoming flow up to $\pm 20^{\circ}$.

The critical speed chambers are worth using when the input process is highly non-stationary, since such chambers ensure 1.5-2-fold inertia reduction as compared to the deceleration chambers. 
For high supersonic speeds of the oncoming flow, both critical speed chambers and deceleration chambers can be used. Deceleration chambers must have a longitudinal flow-around, and in order to ensure the minimum flow distortion, outflow openings must be located both on the side surfaces of the converging part of the chamber and along the chamber axis.

\title{
References
}

[1] Vickers, P.T. (1964) Proper Probes Keep Thermocouples Reading True // SAE J, 2(12), $54-57$.

[2] Vas, I.E. (1972) Flowfield Measurements Using a Total Temperature Probe at Hypersonic Speeds // AIAA J, 10(3), $317-323$. http://dx.doi.org/10.2514/3.50093.

[3] Hukhman, A.A., and Iliukhin, N.V. (1951) Fundamentals of the Theory of Heat Transfer at High Speed Gas Flow, "Mashgiz" Publ. in Moscow, 226 p. (in Russian)

[4] Fedynets,V.O. (2007) Principles of Design and Technological Optimization of High Speed Gas Flow Temperature Transducers, Lviv Polytechnic National University Proceedings, Automation, Measurement and Control, 574, 111-115. (in Ukrainian)

[5] Fedynets,V.O. (2007) Mathematical Model of the Gas Dynamic Subsystem of Gas Flow Temperature Transducers, Abstracts of the 15th International Metrology Seminar, Methods and Techniques of Signal Processing in Physical Measurements (Lviv-Rzeszów), 21 p.

[6] Moffat, R.J. (1962) Gas Temperature Measurement; Temperature, its Measurement and Control in Science and Industry / Editor-in-Chief Charles M. Herzfeld, Reinhold Publishing Corporation in NY, 3(2), 553-571.

[7] Preobrazhenskiy, V.P. (1978) Thermal Engineering Measurements and Devices, "Energy” Publ. in Moscow, 704 p. (in Russian)

[8] Loitsyanskii, L.G. (1973) Mechanics of Liquids and Gases, "Nauka” Publ. in Moscow, 904 p. (in Russian)

\section{Оптимізація газодинамічної підсистеми перетворювачів для вимірювання температури газових потоків}

\author{
Василь Фединець, Ігор Васильківський, Ярослав Юсик \\ Національний університет «Львівська політехніка», вул. С. Бандери, 12, Львів, 79013, Україна
}

\begin{abstract}
Анотація
Основні види похибок, які мають місце в процесі вимірювання температури газових потоків (в тому числі і потоків енергоносіїв) визначаються умовами теплового балансу при взаємодії чутливого елемента перетворювача температури (ПТ) з газовим потоком через конвекцію, випромінювання та теплопровідність. Необхідно враховувати також обмежені можливості ПТ без запізнення слідкувати за змінами температури потоку. При великих швидкостях газового потоку (більше 50 м/с має місце також похибка, обумовлена перетворенням частини кінетичної енергії потоку в теплову (так звана “швидкісна" складова похибки). Повне аналітичне дослідження сумісного впливу всіх основних чинників на загальну похибку вимірювання температури газового потоку конкретним ПТ практично неможливе, оскільки деякі залежності, що описують характер впливу того чи іншого чинника, можуть бути визначені тільки експериментально. Тому на практиці аналізують кожний вид похибки окремо з припущенням, що решта ії видів відсутні, а загальну похибку вимірювання розглядають як суперпозицію окремих видів похибок. Для зручності проведення аналізу ПТ представлено у вигляді окремих елементарних ланок зі своїми складовими похибки. ПТ для вимірювання температури газових потоків представлено у вигляді трьох послідовно з'єднаних ланок: газодинамічної, теплової та електричної. Газодинамічна підсистема перетворює термодинамічну температуру $T(\tau)$ газового потоку на вході ПТ в температуру гальмування $T_{\Pi т}(\tau)$ на вході в термочутливий елемент і характеризується “швидкісною” складовою похибки. Визначальною характеристикою газодинамічної підсистеми $є$ коефіцієнт відновлення ПТ. Тому в статті розглянуто способи та засоби для забезпечення постійності коефіцієнта відновлення.
\end{abstract}

Ключові слова: газовий потік; вимірювання; теплообмін; температура; перетворювач температури. 